\title{
Developing a Personnel Capacity Indicator for a high turnover Cartographic Production Sector
}

\author{
Flávia Mandarino $^{\mathrm{a}}$ and Leonardo A. M Pessôa ${ }^{\mathrm{b}}$ \\ ${ }^{a}$ Centro de Hidrografia da Marinha, Niterói, RJ, Brazil; flavia@marinha.mil.br \\ ${ }^{b}$ Centro de Análises de Sistemas Navais, Rio de Janeiro, RJ, Brazil; pessoa@marinha.mil.br
}

\begin{abstract}
This paper describes a framework for development of an indicator for human re-sources capacity management in a military organization responsible for nautical chart production. Graphic chart for the results of the model COPPE-COSENZA (Cosenza et al. 2015) is used to properly present the personnel capacity within a high people turnover environment. The specific skills for the nautical charts production allied to the turnover rate require continuous and adequate personnel in-corporation and a capacity building through education and on-the-job training. The adopted approach for the study establishes quantitative values to fulfill quality requirements, and also presents graphically a profile for the human resources on a specific job to facilitate diagnosis and corrective actions.
\end{abstract}

Keywords: Nautical Charts Production Management, Capacity Indicators, Coppe-Cosenza model

\section{Introduction}

Developing an indicator for personnel capacity building in an organization is not always a simple task. Particularly when the organization has to educate and train its technicians to reach the skills needed for specific jobs. And it gets more difficult when there is a high turnover rate on critical sectors.

This paper aims to present an indicator for the human resources capacity management on a military organization (Brazilian Navy Hydrographic Center $\mathrm{CHM}$ ), which is responsible for producing and maintaining Brazilian nautical charts. CHM looks after a high and continuous demand for updating its cartographic products.

Human resources management in an organization with a high personnel turn-over, peculiarity of the military, makes inadequate an approach based only on the skills improvement. Moreover, the nautical cartography processes are only done by this organization in Brazil and the education and training must be done on the job at the production sector. Even those technicians, who had been gone through cartography training outside the organization, must learn nautical cartography skills on the job.

Initially, the purpose of the creation of the indicators was to attend human re-sources capacity measuring for the ISO9001 requirements. It was required to measure the work force capacity for each job on the nautical cartography activities. People turnover put more challenges for the indicator creation, as it was an initial assumption, which led the managers to think about knowledge management and renovation.

Looking deeper into the problem, it was verified that the indicator should ad-dress somehow the turnover related issues. It was not only sufficient to have human resources qualified for the jobs, but mentors and trainees in specific proportions for the jobs as well.
A synthetic measure might not present correct conditions for the human re-sources management. For this reason, a proposal was developed to present graphically the results allied to a numeric indicator obtained by a multi-criteria method

So as to present a reasonable methodological structure, section 2 presents theoretical aspects on the indicators and the multi-criteria model Coppe-Cosenza (Co-senza et al. 2015), used in this paper. Section 3 applies the proposed approach to the nautical charts new editions production at CHM. Section 4 presents a discussion about the results followed by a brief conclusion.

\section{Methodology}

\subsection{Indicators}

The interest of decision aid support for cartography is found in Webb; Riding (2013), where several methodologies are presented, from Bayesian Networks to Monte Carlo Simulation. Different techniques can be used to provide better deci-sions and improve quality and productivity. But in order to do so, performance measurement is necessary for goals definitions, and it can be done through quan-titative or qualitative indicators (Popova; Sharpanskykh 2010)

Goal related indicators can also become "policy instruments" and can be classified in four types (Barnetson; Cutright 2000):

- Authority-based instruments

- Incentive-based instruments

- Capacity-building instruments

- Hortatory instruments

This paper intends to address Capacity building instruments, dedicated to "in-vest in intellectual, material or human resources to enable activity", and Hortatory Instruments that "signal priorities and propel action by 
appealing to values via symbols". (Barnetson; Cutright, 2000).

Besides, Marr et al. (2004) highlights the importance of knowledge as strategic resource: "knowledge is a resource that forms the foundation of the company's capabilities become competencies". Therefore, knowledge must be evaluated by the organization. Such importance for Nautical Cartography can be seen in Ryan (2014), who presents the relationship between knowledge and productivity.

Barnetson; Cutright (2000) shows that performance indicators have important information embedded as they present the questions raised for its construction "by focusing our attention on specific aspects of institutional performance".

Despite of its importance, measuring knowledge is not an easy task. Moreover, it is not easy to find a structured manner to generate an indicator for that. One possible reason is that frequently indicators are built on an informal and ad-hoc way (Popova; Sharpanskykh, 2010).

In this paper an indicator for personnel capacity is presented, showing the steps used on its construction. This indicator is built on an environment with a personnel high turnover rate.

Therefore, the sector needs a profile of personnel with different skill levels al-lowing a soft transition, a sustainable production rate and the continuous personnel development.

\subsection{Proposed approach}

This paper proposes the following steps in order to measure the personnel capacity in a sector of an organization, in charge of nautical charts production.

- analysis of the production processes for nautical charts new editions;

- identification of the technical jobs embedded in the processes;

- establishment of a qualitative graduation for the skill levels for each technical job;

- definition of a desired profile for the personnel allocation on each job;

- evaluation of the existing allocation;

- graphical comparison between desired and existing profile; and

- Indicator calculation.

The analysis of the production processes points out which technical jobs to be considered. Only those inherent to the production of nautical charts new editions were considered on this study.

From the processes mapping, pertinent technical jobs were identified. It is noteworthy that the processes, for this study, are considered adequate.

Quantitative values (number of human resources) are established for each job and its different skill levels.

Thus, for each technical job it is necessary to create a qualitative scale to rep-resent the skill levels. This scale, based on qualitative parameters, must be easily understood by the sector manager, who is going to classify each professional ac-cording to the defined levels.

Also, the manager must elaborate a profile for each job, defining the number of the technicians for each level to support the desired productivity of the sector.

The proposed model was created for this specific context (nautical charts production), where new resources constant supply and on-the-job training are necessary. It implies that is also necessary to plan expertise transfer, so it is desirable to have a balanced workforce among the skill levels, and not only experts, who are normally close to retirement.

We suggest planning the ideal composition beforehand to the current situation study, so as to avoid the bias that might occur.

Then it is performed a graphical comparison of the current situation with the desired one, for each job and level, providing a deeper diagnostic and a better prognostic. It can help to properly carry out preventive and corrective actions.

Finally, a capacity indicator is generated for the organization.

\subsection{COPPE-COSENZA model}

Cosenza et al. (2015) presents a multi-criteria model called COPPE-COSENZA. It is based on fuzzy logic and it was originally designed as a decision aid to allocation for economic spaces.

The model applies a matrix structure to two sets: set A, defining required needs, and a set $\mathrm{B}$ of provided potentialities.

Set A represents the required needs, classified in four categories, based on their importance: Crucial $(\mathrm{Cr})$; Conditional (C); Little Conditioning (LC); and Irrelevant (Ir).

The values attributed to the conditions $\mathrm{Cr}, \mathrm{C}, \mathrm{LC}$ and $\mathrm{Ir}$ are such that $\mathrm{Cr}-\mathrm{C}=\mathrm{C}-\mathrm{LC}=\mathrm{LC}-\mathrm{Ir}=$ constant. This assumption makes the use of this ordinal scale feasible, as though it were an interval scale.

On the other hand, the provided potentialities (set B) are represented on the following linguistic variables: NonExistent; Empty; $\{0\}$; Weak; Regular; Good; and Superior.

On this paper, a simplified approach is adopted, which discards the Non-Existent and Empty classifications due to are not applicable to this paper context.

Each required factor is evaluated by the provided potentialities using an aggre-gation matrix. Such matrix depends on the nature of the problem. For this paper study, the aggregation matrix is extracted from Pessôa (2015), and it is presented on Table1.

\begin{tabular}{l|r|r|r|r|r} 
& $\{0\}$ & Weak & Regular & Good & Superior \\
\hline $\mathrm{Ir}$ & 1 & 1 & 0 & $-1 / 2$ & -1 \\
$\mathrm{LC}$ & 0 & 0 & 1 & 0 & $-1 / 2$ \\
$\mathrm{C}$ & $-1 / 2$ & $-1 / 2$ & 0 & 1 & 0 \\
$\mathrm{Cr}$ & -1 & -1 & $-1 / 2$ & 0 & 1
\end{tabular}


Table 1. Agreggation Matrix - Adapted from Pessôa (2015)

This aggregation matrix deals with "tailor-made" problems, which the "distance" between the required and the existent situation is intended to be the smallest possible. It means that observations with a lower or a greater level than required will contribute to a worse result.

Some properties regarding linguistic modifiers (Cosenza, 2015) will not be captured by this work. Nevertheless, the model still preserves flexibility regarding the linguistic variables scales which are defined by the manager.

\section{Practical Application and Discussion}

This paper describes an example application of the COPPE-COSENZA model on the Brazilian military organization responsible for the nautical charts production. Presented data of the staff (quantitative and qualitative) are hypothetical, created only for this study. Nevertheless, the model may be applied to the real situation.

\subsection{Production process for nautical charts new editions}

An organization in charge of the official nautical charts is responsible to produce and maintain several products. Nautical charts must be updated and this requirement is achieved by issuing new editions, new charts, reprints and blocks, as mentioned in Spittal (2003).

Among the products for maintaining the nautical charts, new editions (or new charts) are the most time consuming task. Besides, its processes need the most skilled technicians.

This paper focuses on part of the processes, adopted by CHM, for the production of a nautical chart new edition, including its modalities on paper and digital (Electronic Navigational Chart - ENC).

The workflow for the production of a new edition of a nautical chart is presented on Figure 1.

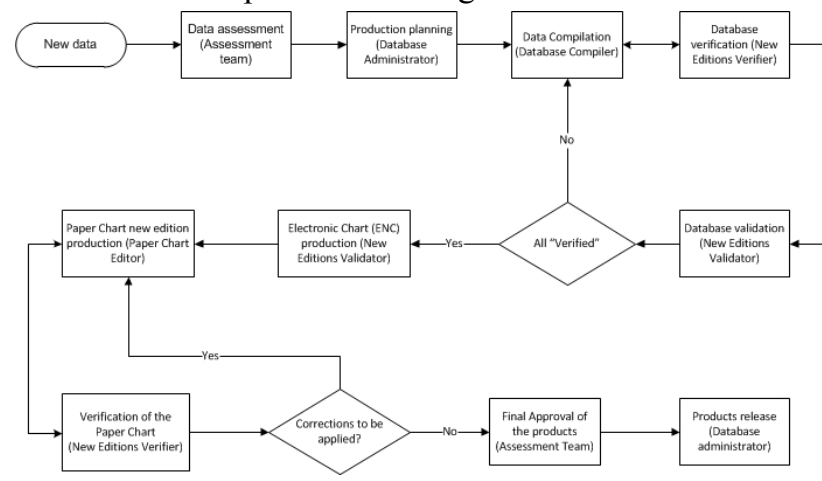

Fig. 1. Workflow for the production of a new edition of a nautical chart

For the presented workflow, following jobs are required:

- Database compiler - CBD: In charge of data organization, analysis and se-lection and data loading onto the production database;
- $\quad$ Paper charts editor - ECP: In charge of the paper chart elaboration within the database environment;

- New editions verifier - VER-NE: Responsible for the validation of the data-base information and the paper chart contents;

- New editions validator - REV-NE: In charge of the final validation of the database and of the Electronic charts (ENC) production; and

- Database administrator - GER-PROD: Responsible for assigning the data and tasks on the production system.

- Assessment team personnel - responsible for the production management.

\subsection{Human Resources}

For each job presented on section 3.1, quantitative values were fictitiously created which would reflect the ideal number of technicians to support the annual planned productivity of nautical charts new editions (table 2)

\begin{tabular}{l|r} 
Job & Quantity \\
\hline CBD & 9 \\
ECP & 13 \\
VER-NE & 6 \\
REV-NE & 5 \\
GER-PROD & 5
\end{tabular}

Table 2. Ideal staff - quantity

\subsection{Qualitative scale for capacity evaluation}

For each job, it was created a capacity evaluation scale of four skill levels, based on Ryan (2014). Every human resource allocated on the job is classified in-to one level, based on specific requirements for that job. The levels are described below:

- Basic: knows very briefly the process and it is learning the procedures for that specific job;

- Intermediate: knows all the process, performs the job, but needs a mentor all the time to support his activity;

- Advanced: knows all the process and perfectly performs the specific job, without the need of a mentor; and

- Expert: knows in details all the process and the specific job and can act as a mentor for the human resources on that job.

\begin{tabular}{l|r} 
Skill grade & level \\
\hline Basic & $\mathrm{A}$ \\
Intermediate & $\mathrm{B}$ \\
Advanced & $\mathrm{C}$ \\
Expert & $\mathrm{D}$
\end{tabular}

Table 3. Skill levels grade

\subsection{Ideal profile for the staff on each job}

As stated before, the cartographic sector must produce nautical charts following an annual production program. 
This program establishes which new editions will be produced and it is based on external criteria related to the safety of navigation. However, the actual production competence of the organization must be considered. It is noted that the adherence of the current staff and the ideal profile, including quantity of resources on each job and level, must be taken into consideration on the production planning.

Table 4 below presents the human resources quantities on each level (described on 3.3) of each job which are needed for a hypothetical production planning.

\begin{tabular}{l|c|c|c|c} 
& $\mathrm{A}$ & $\mathrm{B}$ & $\mathrm{C}$ & $\mathrm{D}$ \\
\hline CBD & 1 & 3 & 4 & 1 \\
ECP & 2 & 4 & 5 & 2 \\
VER-NE & 1 & 2 & 2 & 1 \\
REV-NE & 1 & 1 & 2 & 1 \\
GER-PROD & 1 & 1 & 2 & 1
\end{tabular}

Table 4. Human resources for each job and level

\subsection{Evaluation of the "existing allocation"}

For this paper the existing staff was also simulated due to didactic purposes.

It is observed on the real world that a human resource might have expertise on more than one job. In this work, though, it is conceived that the human resources are allocated only to one job.

In order to support human resources allocation, Table 5 presents the skill levels of all the resources for each job. It gives the information to the production man-ager so as to allocate the resources.

\begin{tabular}{|c|c|c|c|c|c|}
\hline Resource & CBD & ECP & $\begin{array}{r}\text { VER- } \\
\text { NE }\end{array}$ & $\begin{array}{r}\text { REV- } \\
\text { NE }\end{array}$ & $\begin{array}{r}\text { GER- } \\
\text { PROD }\end{array}$ \\
\hline ALFA & D & D & B & B & 0 \\
\hline BRAVO & B & B & B & B & A \\
\hline CHARLIE & B & A & B & B & B \\
\hline DELTA & B & A & B & B & A \\
\hline ECHO & A & A & 0 & 0 & A \\
\hline FOXTROT & A & $\mathrm{C}$ & A & A & A \\
\hline GOLF & A & A & $\mathrm{C}$ & $\mathrm{C}$ & A \\
\hline HOTEL & D & A & 0 & 0 & $\mathrm{D}$ \\
\hline INDIA & A & A & A & A & A \\
\hline JULIET & A & 0 & 0 & 0 & A \\
\hline KILO & D & D & C & C & A \\
\hline LIMA & B & A & A & A & A \\
\hline MIKE & B & $\mathrm{C}$ & A & A & A \\
\hline $\begin{array}{l}\text { NOVEMB } \\
\text { ER }\end{array}$ & B & A & A & A & A \\
\hline OSCAR & A & A & A & 0 & A \\
\hline PAPA & A & A & 0 & 0 & A \\
\hline QUEBEC & A & A & B & 0 & A \\
\hline ROMEO & $\mathrm{C}$ & D & $\mathrm{C}$ & B & D \\
\hline
\end{tabular}

Table 5. Human resources for each job and level
Despite of the overall evaluation shown on Table 5, the resources classification will be determined by the allocation. Table 6 presents how the human resources were classified due to their allocation on the proposed scenario.

\begin{tabular}{l|r|r} 
Resource & Allocated Job & Skill Level \\
\hline ALFA & CBD & D \\
BRAVO & ECP & B \\
CHARLIE & GER-PROD & B \\
DELTA & CBD & B \\
ECHO & CBD & A \\
FOXTROT & ECP & C \\
GOLF & VER-NE & C \\
HOTEL & GER-PROD & D \\
INDIA & CBD & A \\
JULIET & CBD & A \\
KILO & REV-NE & C \\
LIMA & CBD & B \\
MIKE & ECP & C \\
NOVEMBER & CBD & B \\
OSCAR & VER-NE & A \\
PAPA & ECP & A \\
QUEBEC & VER-NE & B \\
ROMEO & GER-PROD & D
\end{tabular}

Table 6. Human resources skill level on allocated job

It is noted that the allocation problem is, per si, very relevant for improving the capacity of the sector. This specific discussion about optimization methods for the presented situation is not on the scope of this paper though.

\subsection{Graphical comparison}

For each job it is possible to calculate the gap between the existing allocated resources on each skill level and the ideal quantities. As an example, table 7 and figure 2 present the results for the Database Compiler job.

\begin{tabular}{l|r|r|r|r} 
& CBD A & CBD B & CBD C & CBD D \\
\hline Ideal & 1 & 3 & 4 & 1 \\
Allocated & 3 & 3 & 0 & 1
\end{tabular}

Table 7. Human resources for each job and level

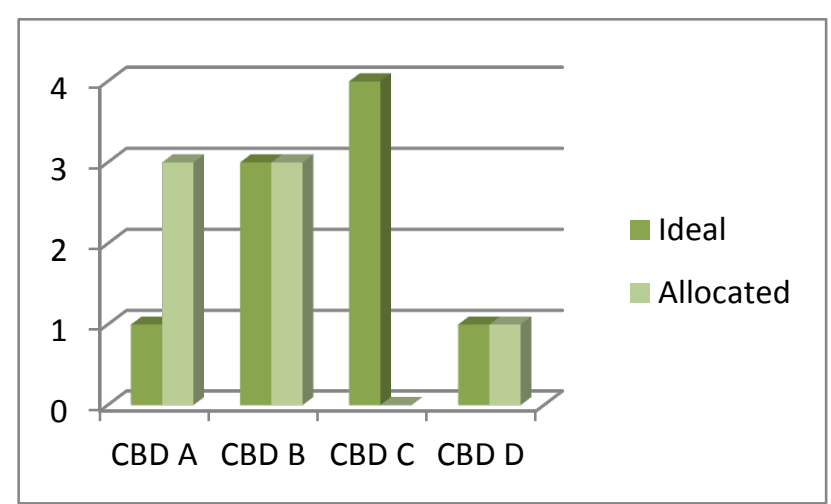


Fig. 2. Comparative graphic for Database Compiler job (CBD)

From the Figure 2, it is possible to easily visualize the impact that an eventual dismissal of the resource ALFA (skill level D on the capacity of the Database Compiler job) might have on the production due to the absence of resources on level $\mathrm{C}$. Reminding that the resources on level $\mathrm{B}$ need a mentor of level $\mathrm{D}$ and there is no one on level $\mathrm{C}$ to reach uppermost level in a reasonable time.

This analysis may induct the manager to allocate resources HOTEL and KILO (both classified as D for $\mathrm{CBD}$ job) or resource ROMEO (skill level C) to maintain their capacity on the job and to be ready to eventually minimize the exit of re-source ALFA, in case of need. Clearly, any reallocation must be analyzed considering other jobs impact as well.

\subsection{Indicator Calculation}

Calculation of the indicator requires the set of a quantitative interval for the linguistic variables Ir - LC $\mathrm{C}$ - Cr. In this procedure the manager must define quantitative ranges to correspond to the linguistic variables.

We presented an initial suggestion using the minimum and maximum needed quantities for each job as parameters for comparison. For CBD job, the mini-mum and maximum quantities are 1 and 4, respectively. So we suggested 1 as the difference between the linguistic variables. Likewise the attendance scale (Weak, Regular, Good and Superior) were defined so as to preserve the aggregation matrix correspondence. However, the manager decided to change the evaluation scale in order to represent his perception, giving the values presented on table 8 .

\begin{tabular}{l|r|r} 
Required & Attendance & Quantity \\
\hline Irrelevant & Weak & 0 \\
Little Conditioning & Regular & $1-2$ \\
Conditioning & Good & 3 \\
Critical & Superior & 4 or more
\end{tabular}

Table 8. Quantitative values evaluation grades for CBD job

Based on table 8 , it is possible to evaluate the situation and obtain the levels scores, presented on table 9.

\begin{tabular}{l|r|r|r|r}
$\begin{array}{l}\text { Factor } / \\
\text { Level }\end{array}$ & $\mathrm{A}$ & $\mathrm{B}$ & $\mathrm{C}$ & $\mathrm{D}$ \\
\hline Needed & $\mathrm{LC}$ & $\mathrm{C}$ & $\mathrm{Cr}$ & $\mathrm{LC}$ \\
Existing & $\mathrm{G}$ & $\mathrm{R}$ & $\mathrm{W}$ & $\mathrm{R}$ \\
\hline Result & 0 & 0 & -1 & 1
\end{tabular}

Table 9. Quantitative values evaluation grades for CBD job

The ideal result would be achieving 1 for all the CBD levels, what could represent the perfect attendance to the required needs. Therefore an aggregated evaluation for CBD job (the sum of all levels) would be ideally 4 .

In the presented case such aggregated score is 0 . Such score can be a comparison parameter among all jobs, indicating how the allocation of resources may impact the jobs. And the individual level scores (for each job) can show which factors are prone to improvement.

The model allows simultaneous evaluation of all jobs, obtaining an aggregated score for each job, and for each considered level. So it is also a tool for the man-ager to compare different resource allocations, becoming a decision aid.

\section{Conclusions}

This paper presents an organized manner for generate capacity indicators in a organization responsible for cartographic production. The model aims to contribute to the knowledge management for an organization in which personnel is subject to frequent turnover. The model acts as "Capacity-building instrument" or as "hortatory instrument", as defined by Barnetson; Cutright (2000).

The model uses graphical aspects and adapts the COPPECOSENZA model (Cosenza et al. 2015) to provide a personnel capacity indicator. It allows simultaneous comparison among different skill levels and jobs, even with different quantitative human resources.

By presenting a numeric evaluation of each job allocation, it is possible to envisage its use in an interactive manner, where the manager can evaluate personnel allocation decisions beforehand. Future works could integrate the model to optimization techniques (e.g. Integer Linear Programming)

The model does not allow the use of linguistic modifiers (Cosenza et al 2015). Nevertheless, it provides an evaluation based on adequate values and motivates a rational use of human resources, without excesses.

\section{References}

BARNETSON, B. O. B.; CUTRIGHT, M. Performance indicators as conceptual technologies. Higher Education, v. 40, p. 277-292, 2000.

COSENZA, C. A. N.; DORIA, F. A.; PESSÔA, L. A. M. Hierarchy Models for the Organization of Economic Spaces. Procedia Computer Science, v. 55, p. 82-91, 2015. Elsevier Masson SAS.

DANISH GEODATA AGENCY. Behind the Nautical Chart. 2013.

MARITIME SAFETY. Final Guidelines for Good Practice for Hydrographic Surveys in New Zealand Ports and Harbours. New Zealand, 2004.

MARR, B.; SCHIUMA, G.; NEELY, A. Intellectual capital - defining key performance indica-tors for organizational knowledge assets. Business Process Management Journal, v. 10, n. 5, p. 551-569, 2004.

PESSÔA, L. A. M. Multimetodologias Aplicadas para o equilíbrio de oferta e demanda de ofi-ciais da Marinha Mercante, 2015. Universidade Federal do Rio de Janeiro.

POPOVA, V.; SHARPANSKYKH, A. Modeling Organizational Performance Indicators. Information Systems, v. 35, n. 4, p. 505-527, 2010. 
RYAN, J. Doing More with Less by Leveraging People and Technology. IIC Technologies Workshop, 2014. Vancouver.

SPITTAL, J. Definitions for Hydrographic Chart Production. 2003. 